\title{
A Note on Numbers and Names
}

This is a study of political economy; therefore, it contains a great many numbers and names, both of which are problematic in Brazilian studies.

Most of the economic data I have used were collected-sporadically- by understaffed and underfinanced Brazilian government agencies. Hence there are no reliable figures on such important items as foreign investment, the balance of payments, or the gross domestic product. National banking statistics were collected first in the late 1920s; the only national industrial censuses were taken only in 1907 and 1919 and both, particularly the first, are of questionable accuracy. Even data on international trade, the most assiduously gathered of all, are replete with errors caused by inefficiency, inconsistencies in categorization, contraband, and other forms of cheating. Federal deputies often did not even know the extent of the federal debt and deficit. Most state and municipal data are no more reliable.

Even where numbers are rather trustworthy, they are problematic because of inflation, oscillating exchange rates, and sharp regional differences in levels of development. Historical series and, indeed, any comparison over time, are troublesome because inflation and currency devaluations hinder calculations of real values. National-level figures such as GDP and the inflation rate do not reflect the reality of parts of Brazil that were only partially in the money economy.

And yet I use numbers. Since most generalizations require some sort of numerical reference, crude though it may be, I have provided numerical estimates. I have rounded off most figures to reflect the level of certainty. Most are probably quite close to the reality; some, maybe less so. In either case, the numbers should be understood as ballpark figures, some fit nicely in Little League parks; others perhaps belong in Rio's Maracana. I do not believe that a correction of my estimates by 10 percent or even one-third would appreciably alter my conclusions.

Names are another problem. Brazilian usage can be somewhat confusing. People with uncommon first names were usually called by that name; hence, Presidents Deodoro, Floriano, and Washington Luís. Common first names 


\section{x Note}

usually led to the use of one or two last names; thus we have Presidents (Manoel) Campos Sales, (Francisco) Rodrigues Alves, and (Afonso) Pena. Brazilian Portuguese has undergone several orthographic modifications since the First Republic to simplify the language. I have spelled names as the person did himself, but employed modern spellings for other Portuguese words. 